\title{
Blessing or a Curse ? Exploring the Identity and Lived Experiences of Australian, Lebanese- Muslim Women with Hearing Impairment
}

\author{
Ayah Wehbe \\ School of Social Sciences \\ University of New South Wales (UNSW) Australia \\ E-mail: ayah.wehbe@gmail.com
}

\begin{abstract}
This paper explores the identity and experiences of women with hearing loss who come from an ethnic background. Semi-structured interviews were conducted with eight women living in Sydney who came from an Australian, Lebanese-Muslim background and experienced living with hearing loss. As the researcher is herself an Australian, Lebanese-Muslim woman with hearing loss, auto-ethnography was used to explore how the women from a similar background navigated their identities and whether they perceived their hearing loss as a 'blessing' or a 'curse'. The findings suggested that most of the women identified themselves by their hearing loss first, followed by their identity as a Muslim. Being a Muslim was important as their religion allowed them to cope with their identity challenges and accept their hearing loss as a 'blessing' from God. However, cultural stigma, barriers to communication, isolation in the family and community mirrored the 'curse' of hearing loss.
\end{abstract}

Keywords: d/Deaf, Diversity, Identities, Muslim, Australian, Lebanese, Women

\section{I.INTRODUCTION}

The experiences of individuals with hearing impairment, as well as research on the 'Deaf' community, is stereotyped to mean "White or White people, and this must change [1]". Only a small body of research explores the "minority within a minority [2]" or individuals who do not fit in the dominant 'Deaf' community, due to their ethnic and cultural background. Therefore, more research is needed about individuals with hearing loss who come from an ethnic background.

Identity is important for people with hearing loss in the different ways they identify themselves and their hearing impairment. For example, people who are 'Deaf', with a capital $\mathrm{D}$, identify as belonging to the 'Deaf community', a linguistic group who use sign language to communicate [3,4]. People who identify as 'deaf', with a lowercase 'd', refers to those who have a significant hearing loss with no or minimal access to sound and use some use sign language or lip-read to communicate [5], but they are not necessarily members of the Deaf community. Terms like 'hearing impaired' and 'hearing impairment' are commonly used to describe the audiological deficiency or condition [6] and Najarian [4] suggests that identifying someone as 'hearing impaired' may have negative connotations, so 'hard of hearing' is sometimes used instead. This paper will use the term ' $d$ /Deaf' because identity terms are fluid and not always clear [1,5].
d/Deaf women are constantly negotiating their identities and in doing so "carve out places for themselves in the Deaf world, hearing world and the places in between [4]". While Najarian [4] focused on women, they did not explore how d/Deaf women negotiate cultural and ethnic identities. Stapleton [1] explored women who were the "only d/Deaf people in their hearing families and were negotiating racial and ethnic identities" while Foster \& Kinuthia [2] who coined the term "minority within a minority" where individuals experience challenges due to both their deafness and ethnicity, concluded that an individual is a "constellation of many parts, some of which are stronger than others". The limitations of both studies $[1,2]$ included a focus on American college students and with no participant who identified as Muslim or from a Middle Eastern background. Willoughby [7] revealed that over $300 \mathrm{~d} /$ Deaf Australians from different migrant backgrounds, who lived in the state of Victoria, experienced challenges integrating into the Deaf community and accessing support services, but no comparable research has been conducted in the Australian state of New South Wales, specifically the city of Sydney, (where the author is resident) or included women with hearing loss from a Lebanese-Muslim background.

A small body of literature explored Lebanese-Muslim women living in Australia and how they "are constructing blended identities [8]". Women from this group also reported identity challenges due to increasing Islamophobia, to such an extent that some choose not to identify as Lebanese or Muslim [9]. Because of their visibility, Muslim women in Australia who wear the hijab are often "targeted for acts of racist aggression [8]". Despite this, Poynting [8] concluded women in his study began "taking more interest in their religion, and a number had only recently adopted the hijab". However, there is no research which looks at how Australian, Lebanese-Muslim women who are d/Deaf navigate another dimension of their identity, their hearing loss.

The objective of this study was to explore the identity and lived experiences of women with a hearing impairment who live in Sydney, who identified as Australian and LebaneseMuslim. The research questions in this study are:

(1) How did women with a hearing impairment, from an Australian Lebanese and Muslim background identify themselves and navigate their mixed identity, and 
(2) how did they feel about their hearing-loss i.e. did they perceive it to be a 'blessing' or a 'curse'?

Willoughby [7] stressed the importance of understanding religion and culture for d/Deaf Australians from ethnic backgrounds where religion is central to the lives of many Lebanese living in Australia. Disability in Islam is an important topic with differences between religion and culture

[10]. Bazna \& Hatab [11] argue the Holy Qur'an focuses on "the notion of disadvantage that is created by society" and that society is responsible for improving the conditions of people. They concluded that the perceptions of Muslims towards disability "have been tainted by their local cultures and influenced by outside factors [11]". Lebanese-Muslim cultures in Australia seem to follow this example, where some Muslim families in Western countries prevent their children with disability from attending the mosque, fasting or learning Arabic to protect themselves and their children from social embarrassment and stigma [12]. Poynting [8] explains Lebanese communities in Sydney "seemed like a village in the home country with the gossip and prying eyes to be avoided" indicating stigma exists, influencing perspectives towards people with disability.

Disability is understood through religious and cultural perspectives hence, "some cultures view disabilities as a blessing, while others see it as a curse [12]". Islamic scholar Dr. Amar Nakshawani [10] agrees that some cultures believe disability is a punishment from God, but sometimes it's a blessing or a divine test. Al-Aoufi, Al-Zyoud \& Shahminan

[12] agree disability can be described as a test to accept difficulties in life, especially as Islam requires submission to

God. This relates to the term 'Alhamdulillah' which can be translated as 'All Praise be to God' and is primarily associated with acceptance of their life as a 'blessing' and test from God

[10]. Huning [1] makes references to hearing loss being perceived as either a 'blessing' or a 'curse' arguing it's all a matter of perception. This paper did not investigate the

'blessing and a curse' notion in a binary sense, rather how this religious and cultural perception can have significant impact on the way d/Deaf Australians from a Lebanese- Muslim background are identified and experience the world. By exploring the identity and experiences of Australian, LebaneseMuslim women with hearing loss, this study contributes to the small body of research about d/Deaf women who come from an ethnic or minority background and explores the cultural and religious perspectives influencing the identity and experiences of women with hearing loss.

\section{METHODS}

This research used Auto-ethnography as it is a methodology where "the researcher is the instrument of the research [13]". Born in Sydney, from a Lebanese-Muslim background and growing up with a hearing impairment, the researcher used her lived experience of navigating different identities and challenges and her "own biography as part of the research process [14]". Memo journals were kept, observations were made during community events and other reflective writings posted on the researcher's public Facebook page were used to inform the research and visualizing this narrow and invisible group.

Eight semi-structures interviews were also conducted with women who identified as Australian, Lebanese-Muslim and living in Sydney with a hearing impairment. Ages ranged from 22 to 40 years, two of the participants were single mothers, two were married with children and three required an Australian Sign Language (Auslan) interpreter during the interview. Interviews ran for about an hour and were offered in Arabic, English or Auslan or a mixture of all three. Due to the researcher's hearing loss, it was challenging for her to transcribe the videotaped interviews. Allowing another person to transcribe the interviews provided objectivity "to remedy any researcher biases or selective interpretation of the researcher [5]".

Recruitment was mainly undertaken through collaboration with the Sydney Muslim Deaf Association (MDAS) using a video in Auslan which ensured that materials were accessible for $d /$ Deaf people. With assistance from experienced interpreters, the researcher chose to sign in the video to build rapport with others from a similar background. The final video is available on the researcher's Facebook page, Silent Signs [see 15]. MDAS and other Sydney based organisations such as MuslimCare Australia were invited to share the video and help with recruitment.

Two card activities were used in the interviews which asked participants to choose the card/s that best identified their hearing loss and other identities. Kemmery \& Compton [5] had conducted a card activity during their interviews, asking their participants to choose the card/s that best identified their hearing loss and then to elaborate why. The researcher conducted a similar activity in her interviews with cards labelled 'Deaf', 'deaf', 'hard of hearing', 'hearing impaired', and 'none'. The researcher also added a second activity of her own and used cards labelled 'Woman', 'Lebanese', 'Muslim', 'Australian' and asked participants to place these cards, including the first card they selected, in order of importance and they were then asked to explain their choices. Analysis involved coding data from interview transcripts and reflection memos. The findings were organised into the individual, family and community. This paper will summarize the findings and offer a brief discussion by answering the research questions.

\section{RESULTS AND DISCUSSION}

\section{Question 1: Navigating Different Identities}

The first card activity showed that most of participants identified themselves as 'hearing impaired' or 'Deaf' belonging to the Deaf community and using sign language [3, 4]. Three women identified as 'Deaf' and required an Auslan interpreter for the interviews. Malak ${ }^{1}$ explained, "I'm involved with the Deaf community" and Zaynab said "I am profoundly Deaf". Three participants identified themselves as 'hearing impaired'. Maya explained "I have a moderate to severe hearing loss" and the researcher identified herself as 'hearing

\footnotetext{
${ }^{1}$ All Names are pseudonyms!
} 
impaired', saying "hearing loss is a part of me, not all of me". This was consistent with terms being defined by audiological deficiencies [3, 6]. Two women chose two identity cards, suggesting that identity is fluid [5]. Dana identified herself in relation to her cochlear implant saying she was "hearing implanted" and once they come off she is "fully deaf", while Hanan explained "I have the ability to be part of two different worlds... the hearing world and the deaf world" indicating how women are negotiating identities and carving places in different worlds [4].

In the second card activity, five out of eight participants placed their hearing loss identity first. Sarah explained "you have to let them know" while Rima added that "people need to know I'm Deaf [and] Auslan is my language". Identifying as a 'Muslim' was important and half of them chose 'Muslim' second; over 'Australian', 'Lebanese' or 'Woman'. Sarah argued the importance of the 'Muslim' identity sharing "a lot of deaf people are completely different from me ... and they like going out to [the] club... but I can't." Maya strongly identified herself as an "Australian Muslim Woman" and chose not to place them in order. Dana the only participant that selected her cultural identities before her religion, stated "I'm Australian Lebanese. I was born and raised here". In contrast Sarah, Rima, Malak and Zaynab placed the 'Lebanese' identity, before 'Australian' and Zaynab explained "My family do everything in the Lebanese way." The women's "constellation [2]" of their multiple identities, mirrored Stapleton [1] who concluded that no two experiences in negotiating identities are the same. Sarah emphasised the importance of being Muslim because it "stands out" in the Deaf community while Dana was uncomfortable catching the train to work due to increasing Islamophobic attitudes towards Muslim women in Australia [8]. She explained "I wear a scarf, so I'm identified as a Muslim everywhere I go. I feel very uncomfortable catching a train, so I don't." This also indicated how women faced multiple challenges referring to the argument that being deaf or hearing impaired and a member of an ethnic group "constitutes a double liability [2]". Despite the challenges these women face, they proudly chose to identify themselves as Lebanese or Muslim [9] saying "I follow my family" (Zaynab) and "it's where my family is from" (Fatima). Women also stressed their pride in being Australian because that is their country of birth (Maya, Dana) but the order or constellation of their identities and experience of negotiating their identities, all differ.

\section{Question 2: Experiences a 'Blessing' or a 'Curse'?}

Almost all the women shared how isolated and misunderstood they felt. Malak said "sometimes I feel lonely because... I don't understand what is going on", Dana and Maya "miss out on jokes" and Rima said she "feels like in a corner in a hearing environment". Fatima vented about her marriage and raising six kids and felt isolated by people in the community "gossiping" about her. This is an example of cultural stigma in the Lebanese-Muslim community with "gossip and prying eyes to be avoided [8]". When asked how she felt about these challenges Fatima kept saying things like "That's life" and "I'm happy", as well "Alhamdulillah".

Many women used the expression "Alhamdulillah" (All praise belong to God) when reflecting on how they felt about their hearing loss and other challenges (Al-Zyoud \& Shahminan 2012; 10]. Maya sees her hearing loss as "a blessing from God and I say to myself 'Thank God or Alhamdulillah." Dana reflected during hardships she turned to God and says, "Alhamdulillah I think it really truly did help". The researcher also reflected on her own experiences sharing a moment where she was "close to breaking down and complaining to the Almighty... [but] fought the huge temptation and just said "Alhamdulillah". Results showed that religion is important in allowing women to perceive their hearing loss as a 'blessing' and accept all the challenges they face. Many women in this study also expressed interest in learning more about their religion and even adopting the hijab reflecting Poynting's [8] findings. Zaynab believed being a Muslim was important to her, "but I'm already born into it. I guess it's my responsibility to learn more" while Rima says "I'd love to wear a scarf... I still pray and I still fast, but in regard to the Qu'ran I'm still learning".

While not directly mentioned, the 'curse' of hearing loss resulted from the communication barriers, stigma and isolation these women experienced at home and the community. Half of the women in the study were the only family members with hearing impairment and many of the participants' families did not sign. Sarah reflected she learnt Auslan at school and vented to her parents, "I'm not happy with you all" because they do not sign at home. In situations where language and communication barriers exist, deafness becomes more salient than ethnicity [1, 2]. Many of the women remarked that their families "try their best" (Zaynab) but "sometimes they forget" (Maya).

Apart from barriers in acquiring Arabic and/or sign language, an absence of culturally competent services [6] and a lack of support and institutions catering for the "disadvantaged people [12]" prevented the women from being involved in their community and learning more about their religion. The results showed it was not the case of Lebanese-Muslim families in Australia not allowing women to attend the Mosque, learn Arabic or practice their religion [12], but they faced many barriers in doing so. Malak said she attended Arabic school but "there was no interpreter". Dana also "struggled" to learn Arabic because the teacher did not "understand" and eventually, "gave up" on her.

The women called for more awareness in their family and community and to "understand where we are, how we feel and how we see everything" (Hanan). Greater accessibility for $\mathrm{d} /$ Deaf people is needed in the Lebanese-Muslim community but also in the d/Deaf community to enable inclusion for people from this cultural background. Like Willoughby's (2008) research, some women expressed a desire for a d/Deaf Muslim group where they could learn more about their religion and meet others like themselves. After the completion of this study, the researcher has worked with MDAS and other organisations to increase accessibility and awareness, and 
organised events for the Muslim Deaf Community in Sydney, but more support and awareness is needed about hearing loss in the Australian-Lebanese community to eliminate the "curses' they face.

There are substantial limitations to this study which only focused on a very narrow sample of women with a hearing impairment who are Lebanese-Muslims living in Sydney. More extensive research is needed not only to offer more diversity in $\mathrm{d} /$ Deaf discourse but to also add to the research about Islam and people with a disability.

\section{CONCLUSION}

This study explored the experiences of Australian, LebaneseMuslim women with a hearing impairment and considered whether they perceived their hearing loss as a 'blessing' or a 'curse'. The perception of 'blessing' or 'curse' has been highlighted mostly with reference to culture and religion $[3,10$, 12] The data suggested the women were navigating multiple identities including hearing loss, gender, ethnicity and religion $[1,4]$. The findings are consistent with Foster \& Kinuthia [2] who concluded an individual is a "constellation of many parts" and while results showed that most women considered their hearing loss identity to be "stronger" [2], identifying as Muslim was also significant for the Australian-Lebanese women in this study. Religion allowed the women to cope with all the identity challenges they faced and contributed to their perception of their hearing loss as a 'blessing'. The use of 'Alhamdulillah' and the importance of religion in their lives allowed these women to be thankful, accept their challenges and consider their hearing loss as a 'blessing' [10]. The notion of 'curse' seemed to reflect the isolation, stigma and barriers women with hearing loss experienced within their Lebanese-Muslim family and the wider society.

\section{ACKNOWLEDGMENT}

I would like to thank my supervisor, Dr Charlotte Smedley for all her tremendous support. I would also like to thank Muslim Deaf Association Sydney, my family and friends and the inspiring women who participated in my research for all their assistance. Together, we will continue to create more changes for Muslims with hearing loss in our community and around the world. Alhumdilullah (All praise belongs to God).

For more information check out http://silentsigns.net/.

\section{REFERENCES}

[1] L. Stapleton, "When Being Deaf is Centered: d/Deaf Women of Color's Experiences with Racial/Ethnic and d/Deaf Identities in College" Journal of College Student Development, vol. 56 no. 6, pp.570-586, 2015.

[2] S. Foster \& W. Kinuthia, "Deaf Persons Of Asian American, Hispanic American, And African American Backgrounds: A Study Of Intraindividual Diversity And Identity" Journal of Deaf Studies and Deaf Education, vol. 8 no. 3, pp.271-290, 2003.

[3] D. Huning, Living Well With Hearing Loss, United States: John Wiley \& Sons, 1992.
[4] C.G Najarian, "Between worlds": Deaf Women, work, and Intersections of Gender and ability, United States: Routledge, 2006.

[5] M.A. Kemmery \& M.V. Compton, "Are You Deaf or Hard of Hearing? Which Do You Go by: Perceptions of Identity in Families of Students with Hearing Loss" The Volta Review, vol. 114, no. 2, pp.157-192, 2014

[6] P. Harris, Culturally Competent Disability Support: Putting It into Practice, New South Wales: Multicultural Disability Advocacy Association of NSW, 2004.

[7] L. Willoughby, Catering to a diverse community: the situation and needs of deaf people from migrant backgrounds living in Victoria, East Melbourne: Victorian Deaf Society, 2008. Available: http://www.vicdeaf.com.au/files/editor_upload/File/Research\%20Report s/fullreportcateringtoadiversecommunity.pdf

[8] S. Poynting, "The 'Lost' Girls: Muslim Young Women in Australia", Journal of Intercultural Studies, vol. 30, no. 4, pp. 373-386, 2009.

[9] K. Betts \& E. Healy, "Lebanese Muslims in Australia and Social Disadvantage" People and Place, vol. 14, no. 1, pp. 24-42, 2006.

[10] A. Nakshawani, "Islam and the Disabled" YouTube, Oct. 24, 2015 Available: https://www.youtube.com/watch?v=U0yA2Mi0NLo [Accessed: Oct. 10, 2016]

[11] M.S. Bazna \& T.A. Hatab, "Disability in the Qur'an", Journal of Religion, Disability \& Health, vol. 9 no. 1, pp. 5-27, 2005.

[12] H. Al-Aoufi, N. Al-Zyoud and N. Shahminan, "Islam and the cultural conceptualisation of disability" International Journal of Adolescence and Youth, vol. 17, no. 4, pp. 205-219, 2012.

[13] J.A. Maxwell, Qualitative research design: An interactive approach, 2nd ed, Thousand Oaks, CA: SAGE Publications, 2005.

[14] V. Walker, K. Farquharson, \& D. Dempsey, Qualitative social research: Contemporary methods for the digital age, London: SAGE Publication, 2016.

[15] A. Wehbe, Silent Signs, [Video File] May 16, 2016: Available: https://www.facebook.com/SilentSigns/videos/1196388257062506/ 